Bol. Inst. Oceanogr. Venezuela, 50 (2): 255-272 (2011) 6 Figs., 4 Tabs.

\title{
SECTOR ORIENTAL DEL GOLFO DE CARIACO, VENEZUELA. UNA DESCRIPCIÓN DE SU DINÁMICA HIDROQUÍMICA, PROCESOS, Y DEL ROL DE LA SURGENCIA COSTERA ESTACIONAL
}

\author{
Aristide Márquez ${ }^{1}$, William Senior ${ }^{1}$, Antonio Benitez ${ }^{1}$, Ivis Férmin ${ }^{1}$, Gregorio Martínez ${ }^{1}$ \\ Angel González ${ }^{3}$, Julián Castañeda ${ }^{1}$, Luis Alcalá ${ }^{2}$ \& Ricardo de la Cruz ${ }^{1}$ \\ ${ }^{1}$ Instituto Oceanográfico de Venezuela, Universidad de Oriente, Cumaná, Venezuela. \\ aristd@gmail.com; aristide@sucre.udo.edu.ve \\ ${ }^{2}$ Escuela de Ciencias Departamento de Química, Universidad de Oriente, Cumaná, Venezuela.
}

\author{
${ }^{3}$ Instituto Limnológico, Universidad de Oriente, Venezuela
}

\begin{abstract}
RESUMEN: La dinámica de la hidroquímica y los procesos fisicoquímicos y biológicos fueron estudiados en el sector oriental del golfo de Cariaco. El régimen de vientos y precipitación controlaron de gran manera, la hidroquímica y algunos de los procesos en la zona de estudio. En las aguas de superficie y fondo los promedios mensuales fueron: 25,69 y $25,69^{\circ} \mathrm{C}$ para la temperatura, 35,410 y 35,750 en la salinidad, 23,43 y $23,84 \mathrm{~kg} / \mathrm{m}^{3}$ en la anomalía densidad (Sigma-t); 184,49 y 178,38 $\mu \mathrm{mol} / \mathrm{kg} \mathrm{de} \mathrm{O}_{2} ; 7,98$ y $7,94 \mathrm{de} \mathrm{pH} ; 3,18$ y $4,22 \mu \mathrm{mol} / \mathrm{L}$ en nitrato; 0,45 y $0,60 \mu \mathrm{mol} / \mathrm{L}$ en nitrito y 1,25 y $1,39 \mu \mathrm{mol} / \mathrm{L} \mathrm{de}$ amonio; 25,28 y $26,31 \mu \mathrm{mol} / \mathrm{L}$ para el nitrógeno total. Las concentraciones de fosfato entre superficie y fondo variaron de 0,60 a $0,79 \mu \mathrm{mol} / \mathrm{L}$, mientras que fósforo total fue de 2 y $170 \mu \mathrm{mol} / \mathrm{L}$. Los valores de las concentraciones de clorofila $a$ entre superficie y fondo oscilaron entre 5,19 y $4,33 \mathrm{mg} / \mathrm{m}^{3}$ respectivamente. El ANOVA $(\mathrm{P}<0,05)$, no reveló variación significativa en los valores de las aguas de superficie y fondo, pero si en los meses estudiados. Se detectaron procesos de descomposición de la materia orgánica tipificados por valores de utilización aparente de oxígeno superiores $50 \mathrm{~m} \mathrm{~mol} / \mathrm{Kg}$ y denitrificación $\left(\mathrm{N}^{*}\right)$, los cuales incrementaron los niveles de amonio y disminuyeron los valores del $\mathrm{pH}$ durante la relajación de la surgencia. Hubo un desfase entre los máximos de clorofila $a$ y de los nutrientes, lo cual dio evidencia de que el fosforo, podría ser un limitante de la producción fitoplanctónica, especialmente durante la relajación de la surgencia, cuando el valor de la relación Redfiel aumenta desde $\mathrm{N}: \mathrm{P}=16: 1$ hasta $\mathrm{N}: \mathrm{P}=24: 1$.
\end{abstract}

Palabras clave. Hidroquímica, procesos, surgencia, golfo de Cariaco.

Abstract: The hydrochemical, physical-chemical, and biological dynamics were studied in the eastern waters of the gulf of Cariaco, where wind and precipitation patterns govern these processes to a significant degree. Average monthly values for both surface and bottom waters were respectively as follows: temperature: $25.69{ }^{\circ} \mathrm{C}$ each; salinity: 35.41 and 35.75 units; density anomaly (ó-t): 23.43 and $23.84 \mathrm{~kg} / \mathrm{m}^{3}$; oxygen concentration: 184.49 and $178.38 \mathrm{mmol} / \mathrm{kg} ; \mathrm{pH}: 7.98$ and 7.94 ; nitrates: 3.18 and $4.22 \mu \mathrm{mol} / \mathrm{L}$; nitrites: 0.45 and $0.60 \mu \mathrm{mol} / \mathrm{L}$; ammonium: 1.25 and $1.39 \mu \mathrm{mol} / \mathrm{L}$; total nitrogen: 25.28 and $26.31 \mu \mathrm{mol} / \mathrm{L}$. Phosphate concentrations between surface and bottom waters varied between 0.60 and $0.79 \mu \mathrm{mol} / \mathrm{L}$, whereas those of total phosphorus ranged from 2 to $170 \mu \mathrm{mol} / \mathrm{L}$. Surface and bottom chlorophyll a concentrations ranged from 5.19 to $4.33 \mathrm{mg} / \mathrm{m}^{3}$, respectively. ANOVA $(\mathrm{P}<0.05)$ did not reveal any significant variation between the values studied, but it did show differences between the values for different months. Decomposition of organic matter was detected, as typified by both oxygen utilization greater than $50 \mathrm{mmol} / \mathrm{kg}$ and denitrification $\left(\mathrm{N}^{*}\right)$, which increased ammonium concentration and reduced the $\mathrm{pH}$ during periods of upwelling relaxation. There was an imbalance between the maxima of chlorophyll a and those of nutrients, which evidenced that phosphorus could be an inhibitor of phytoplankton production, especially during upwelling letup, when Readfield ratio increases from $\mathrm{N}: \mathrm{P}=16: 1$ up to $\mathrm{N}: \mathrm{P}=24: 1$.

Key words: Hydrochemistry, processes, upwelling, gulf of Cariaco.

\section{INTRODUCCIÓN}

El golfo de Cariaco forma parte del Mar Caribe suroriental de la costa nororiental de Venezuela, al este de la cuenca de Cariaco, representando uno de los 5 sectores que conforman el área total de distribución y de pesca en el nororiente de Venezuela (Simpson \& GRIfFIthS 1967,
GuZMÁn et al. 1998, Quintero et al. 2002). En su interior desembocan 79 cursos de agua, ríos, quebradas y riachuelos, de carácter intermitente (CARABALLO 1982). Del total, 34 corresponden a la costa sur y 45 a la costa norte. El río más importante de la región es el Manzanares, que descarga en la entrada del golfo que se encuentra en el sector occidental. En la costa sur entre los ríos de mayor 
influencia sedimentaria se encuentran, de oeste a este, los ríos: Tunantal, Guaracayal, Marigüitar, Tarabacoa, Cachamaure y Cariaco, los cuales han contribuido a la formación de los amplios deltas que se distribuyen a lo largo del litoral sur. En el sector norte, específicamente en el sector centro-oriental, muchos de los cursos de agua tienen un recorrido de apenas $2 \mathrm{~km}$, no presentando zonas de planos aluviales, ni deltas, ya que, en la zona no existe un rasgo de plataforma que sirva de depositario a los sedimentos aportados desde la zona continental (CARaballo 1982, Márquez et al. 2005).

Las aguas del litoral costero del golfo de Cariaco están influenciadas por las condiciones meteorológicas, hidrodinámicas, biológicas, geoquímicas, geomorfológicas, ecológicas y por el influjo exógeno de origen antrópico, por ser el receptáculo final de la escorrentía continental, alterando de una u otra forma el equilibrio hidrológico, geoquímico y ecológico (Bonilla 1982, Bonilla 1993, MÁrquez et al. 2005). La hidrodinámica costera de la zona determina el drenaje de material detrítico, orgánico e inorgánico que está en suspensión, hacia los ecosistemas litorales, siendo este hecho especialmente importante en la ecología, en la hidrobiológica y geoquímica marina, debido a que controla los cambios diagenéticos en la columna de agua y en los sedimentos marinos, proporcionando fuentes de energía, alimentos, vitaminas y minerales para las bacterias, flora y fauna (BoniLla et al. 1995). Los procesos de convección y afloramiento en el golfo de Cariaco tienden a desarrollar fenómenos de renovación de las aguas superficiales cálidas por aguas profundas de más bajas temperaturas y ricas en sustancias nutritivas como nitritos, nitratos y fosfatos, estimulando el desarrollo fitoplanctónico junto a diferentes partículas de sedimentos que se depositan y se acumulan sobre la Plataforma Continental, constituyendo de esa manera la riqueza del fondo marino (Rowe et al. 1977, Bonilla et al. 1985). De igual manera, la descomposición de la materia orgánica ocasiona cambios geoquímicos importantes de los elementos biogenéticos contenidos en los sedimentos (relación $\mathrm{C}$ : N: P), los cuales se correlacionan con los procesos de sedimentación y diagénesis (Bonilla et al. 1985). El golfo de Cariaco presenta algunos impactos ambientales debido a tres factores principales: 1) la descarga de los ríos Manzanares (en el occidente) y Carinicuao (en el oriente); 2) los aportes antropogénicos de las poblaciones aledañas y 3) el sistema de corrientes dentro del golfo, el cual transporta a los compuestos contaminantes desde el litoral sur hasta el norte (PNUMA 2009).
A pesar de la gran importancia que representa el golfo de Cariaco, es escasa la información que existe sobre su dinámica hidrogeoquímica, hidrobiología y en especial en el sector oriental, el cual es considerado como uno de los sectores más productivos dentro del golfo. Es por estas razones que la presente investigación tuvo como propósito realizar un estudio sobre las variaciones espacio-temporales de su hidrogeoquímica e hidrobiología, haciendo especialmente énfasis en las variables: temperatura, salinidad, densidad, oxígeno disuelto, compuestos de nitrógeno, fósforo y clorofila a. El estudio también contempló un análisis comparativo de las variaciones de estas variables durante el período de surgencia y su relajación.

\section{MATERIALES Y MÉTODOS}

\section{ÁreA DE ESTUdio.}

El golfo de Cariaco es un ecosistema geográficamente semicerrado ubicado en la costa nororiental de Venezuela, específicamente, al este de la Cuenca de Cariaco, desde los $10^{\circ} 25^{\prime}$ y $10^{\circ} 35^{\prime}$ Lat. N y los $63^{\circ} 38^{\prime} 8^{\prime \prime}$ y $64^{\circ} 13^{\prime}$ Long. W (Fig. 1). Tiene una longitud aproximada de $62 \mathrm{Km}$ en la dirección este-oeste y un máximo de $15 \mathrm{~km}$ de ancho en la norte-sur, con un área aproximada de $642 \mathrm{~km}^{2}$ y un volumen estimado de $31,5 \times 10^{6} \mathrm{~km}^{3}$ (OKUDA, 1981). Las muestras se recolectaron en la zona oriental o saco del golfo, la cual se extiende desde la población de Pericantar hasta la desembocadura del rio Carinicuao y presenta profundidades inferiores a $50 \mathrm{~m}$.

\section{DiSEÑO DEL MUESTREO.}

Se efectuaron muestreos de aguas de superficie y de fondo de manera mensual desde septiembre de 1995 hasta mayo de 1996 en 16 estaciones ubicadas dentro del sector oriental del golfo de Cariaco (Fig. 1). En el caso de las estaciones con profundidades menores a $2 \mathrm{~m}$, el agua de fondo fue recolectada a 1,5 m. En caso de profundidades entre $5 \mathrm{~m}$ y $7 \mathrm{~m}$ se recolectaron a $4,5 \mathrm{~m}$. En profundidades superiores a $10 \mathrm{~m}$ las muestras siempre se recolectaron 1,5 metros por encima del agua en contacto con el fondo. Los datos de velocidad del viento y precipitación fueron proporcionados por la Estación de Meteorología del Instituto Oceanográfico de Venezuela, Universidad de Oriente, Venezuela. Las variables fisicoquímicas temperatura $\left({ }^{\circ} \mathrm{C}\right)$, salinidad, $\mathrm{pH}$, oxígeno disuelto $(\mathrm{ml} / \mathrm{L})$, se determinaron mediante una sonda multiparamétrica Hidrolab modelo Data sonde 4. Las concentraciones de oxígeno disuelto $\left(\mathrm{O}_{2}\right)$ fueron verificadas utilizando el método de Winkler con precisión de $\pm 0,03 \mathrm{ml} / \mathrm{L}$ 


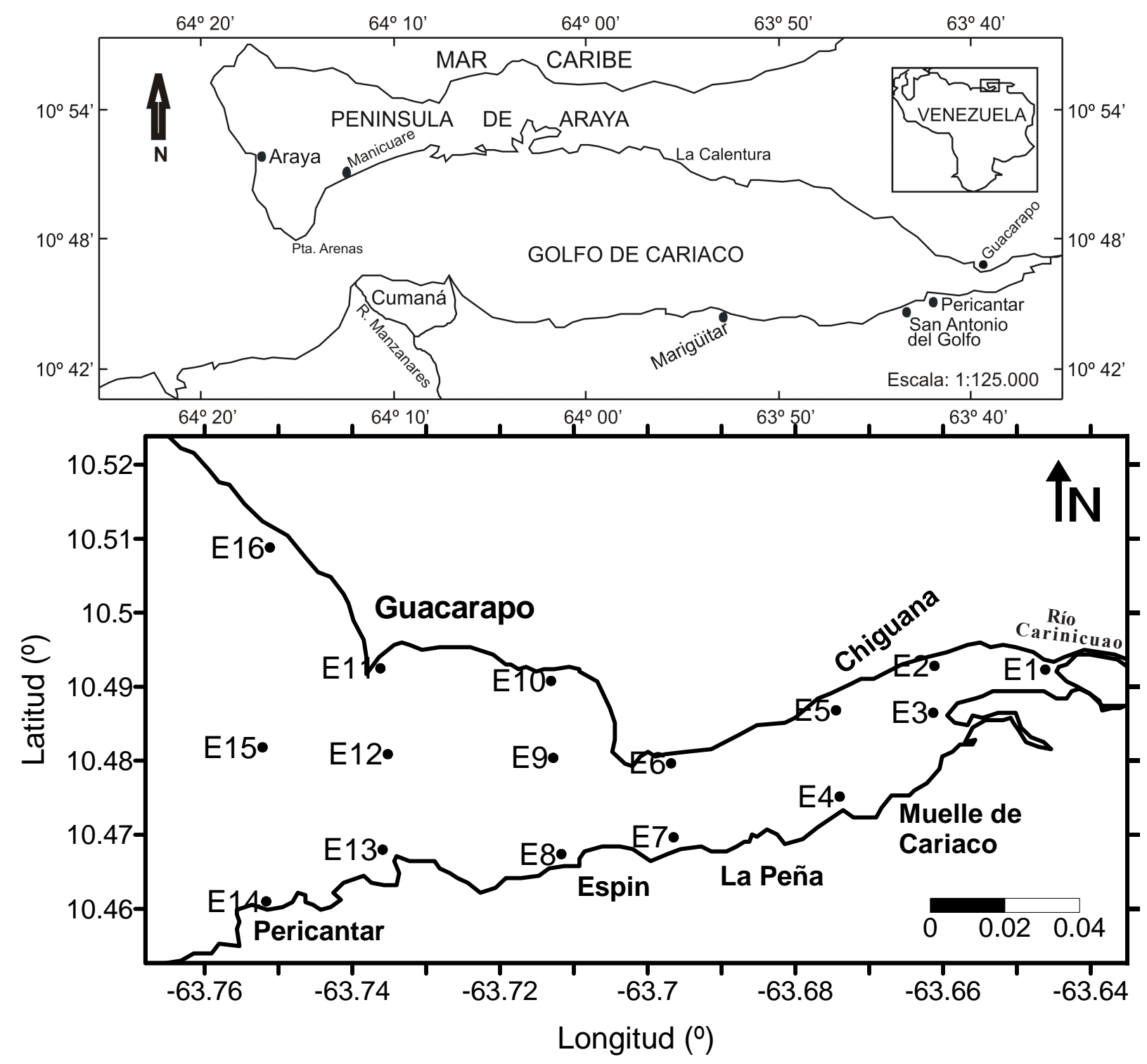

Fig.1. Zona de estudio mostrando las estaciones muestreadas con sus profundidades en el sector oriental del golfo de Cariaco, estado Sucre, Venezuela.

(Aminot \& ChAussePIED 1983), y fueron posteriormente transformadas a unidades de $\mu \mathrm{mol} / \mathrm{kg}$. La utilización aparente de oxígeno (UAO) se determinó por la expresión $\mathrm{UAO}=\operatorname{EXP}(-135,29996+157228,8 /(\mathrm{T}+273,15)-66371490 /$ $(\mathrm{T}+273,15)^{2}+12436780000 /(\mathrm{T}+273,15)^{3}-862106100000 /$ $(\mathrm{T}+273,15)^{4}-(\mathrm{S} *(0,020573-12,142 /(\mathrm{T}+273,15)+2363,1 /$ $\left.(\mathrm{T}+273,15)^{2}\right)-\mathrm{O}_{2}$ (UNESCO 1986), donde $\mathrm{T}$ es la temperatura $\left({ }^{\circ} \mathrm{C}\right)$ y $\mathrm{S}$ es la salinidad práctica.
La anomalia de densidad $\sigma_{t}\left(\sigma_{t}=\rho-1000\right)=$ Sigma-t del agua fue determinada a partir de los valores de temperatura y salinidad, considerando las fórmulas recomendadas por la UNESCO (Fofonof \& Millard 1983). Las concentraciones de nitrito $\left(\mathrm{NO}_{2}^{-}\right)$se determinaron por espectrofotometría visible con una precisión de $\pm 0,01$ $\mu \mathrm{mol} / \mathrm{L}$ (Bendschneider \& Robinson 1952). Las concentraciones de nitrato $\left(\mathrm{NO}_{3}^{-}\right)$se obtuvieron mediante 
un sistema autoanalizador con precisión de $\pm 0,01 \mu \mathrm{mol} / \mathrm{L}$ (WoOd et al. 1967, Treguer \& Le Corre 1975). Los valores de nitrógeno total (NT) y fósforo total (PT) se determinaron de manera simultánea por el método de VALDERRAMA (1981). Para nitrógeno la precisión es de $4 \%$ a nivel de $30 \mu \mathrm{mol} / \mathrm{L}$ y de $11,7 \%$ a nivel de $6 \mu \mathrm{mol} / \mathrm{L}$. Para fósforo total es de $0,2 \%$ a nivel de $5 \mu \mathrm{mol} / \mathrm{L}$ y $2 \%$ a nivel de $1 \mu \mathrm{mol} / \mathrm{L}$. Las concentraciones de amonio $\left(\mathrm{NH}_{4}^{+}\right)$se determinaron por espectrofotometría con precisión de $\pm 0,01 \mu \mathrm{mol} / \mathrm{L}$ (KorolefF 1969), al igual que fosfato (ortofosfato; $\mathrm{PO}_{4}{ }^{3-}$ ) (MurPhy \& Riley 1962). La denitrificación fue determinada por la expresión Nstar $=\left(\mathrm{N}^{*}\right)=\mathrm{NO}_{3}{ }^{-}-16 \mathrm{PO}_{4}{ }^{3-}+2,9 \times 0,87$ (Gruber \& SARmiento 1997). Valores negativos de este parámetro son indicativos de procesos de denitrificación en la columna de agua. Las curvas de calibración para los análisis de nutrientes fueron preparadas con patrones certificados de clase analítica ultra pura, Marine Nutrients Standards BIT (MNSK), de Ocean Scientific International Ltd, SouthDown House, Station Road, Petersfield, Hants GU32 3ET, Great Britain. La determinación de clorofila $a$ (Chl $a)$ se realizó según el método descrito por Lorenzen modificado por STRICKLAND \& PARSONS (1972) para lo cual se empleó un espectrofotómetro GENESYS 8.

Para validar los datos y determinar diferencias entre los meses, estaciones y estrato (superficie y fondo), se aplicaron pruebas estadísticas de Análisis de Variancia Multifactorial y de Rango Múltiple Student-NewmanKeuls. El nivel de significancia utilizado fue de $\mathrm{P}<0,05$ (Tabla 1). Se aplicó también Análisis de Componentes Principales (ACP) para establecer las relaciones entre los diferentes parámetros analizados (JOHNSON \& WICHERN 1992). La separación de los meses correspondientes a surgencia y relajación fue realizada tomado en consideración los valores de celeridad del viento y las observaciones de OKUDA et al. (1978) y OKUDA (1982), quienes explicaron el comportamiento de la señal eólica regional en la zona de estudio, e indican que son distinguibles dos estaciones claramente distinguibles durante el año. Una desde enero hasta mayo con celeridad media anual del viento superiores a $4 \mathrm{~m} / \mathrm{s}$ y que alcanza un valor máximo de $5 \mathrm{~m} / \mathrm{s}$ en marzo cuando la ZCIT se encuentra más desplazada hacia el Ecuador. La otra se extiende desde junio hasta diciembre y está caracterizada por valores medios de celeridad de viento menores a $4 \mathrm{~m} / \mathrm{s}$.

También se consideraron los resultados de las pruebas de ANOVA Multifactorial. Para la separación de los meses de surgencia y relajación, se consideró que existieran diferencias significativas entre los diferentes meses muestreados. Habiendo hecho todas estas comparaciones, se tomaron las temperaturas de superficie menores a $25,50{ }^{\circ} \mathrm{C}$ como temperatura indicativa de afloramiento de las aguas de fondo hacia la superficie. Los meses de surgencia correspondieron a los meses de enero a mayo del año 1996 y los de relajación correspondieron a septiembre a diciembre del año 1995. El software Statgraphics Plus versión 5,1 fue utilizado para las pruebas estadísticas.

\section{RESULTADOS YDISCUSIÓN}

La velocidad del viento (Fig.2A) osciló entre 1 a 6 m/s con un promedio de $3,90 \mathrm{~m} / \mathrm{s}$ durante todo el estudio. Los menores valores se observaron entre septiembre y octubre cuando los valores fueron inferiores a $2 \mathrm{~m} / \mathrm{s}$. Desde enero
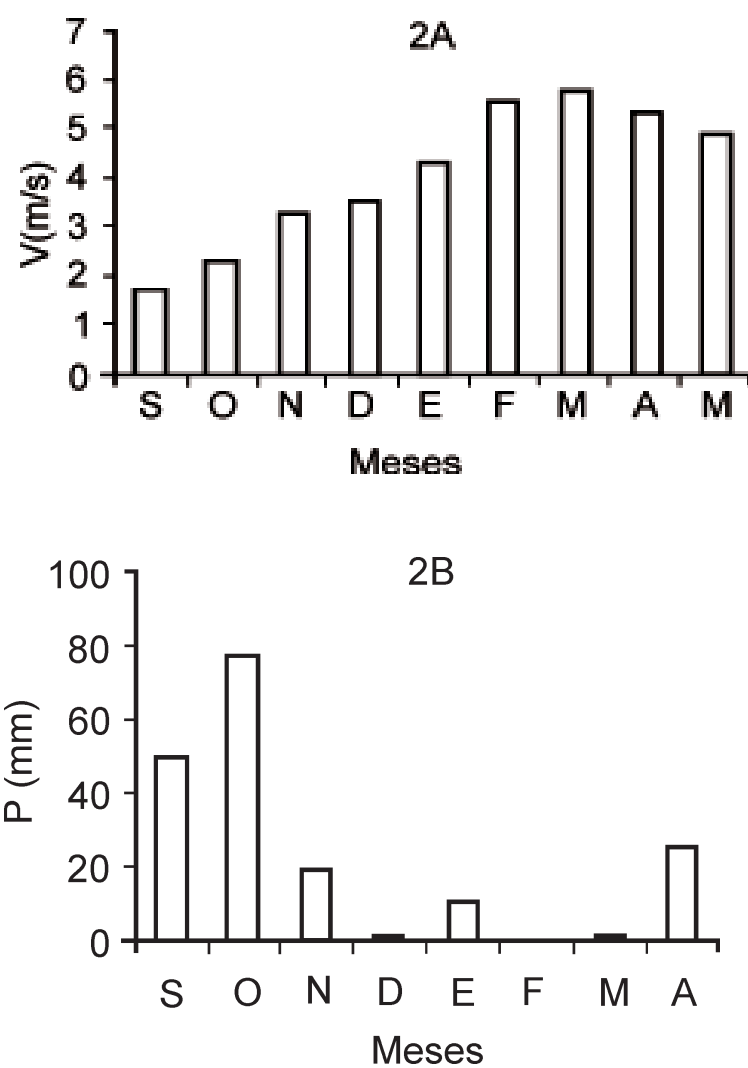

Fig.2. Valores de la celeridad del viento (2A) y la precipitación (2B) en la zona de estudio durante el período septiembre del año 1995 y mayo del 1996. 
El sector oriental del golfo de Cariaco, Venezuela

TABLA 1. ANOVA $(\mathrm{N}=273)$ aplicado a los parámetros hidroquímicos de las aguas del sector oriental del golfo de Cariaco.

\begin{tabular}{|c|c|c|c|c|c|c|c|}
\hline Variable & Factores & $\mathrm{F}$ & $\mathrm{P}$ & Variable & Factores & $\mathrm{F}$ & $\mathrm{P}$ \\
\hline \multirow{3}{*}{$\mathrm{T}\left({ }^{\circ} \mathrm{C}\right)$} & Mes & 600 & $0,00010^{*}$ & \multirow{3}{*}{$\mathrm{NO}_{2}^{-}$} & Mes & 68 & $0,00010^{*}$ \\
\hline & Estación & 12 & $0,00010^{*}$ & & Estación & 4,70 & $0,05 \mathrm{NS}$ \\
\hline & Estrato & 51 & $0,00010^{*}$ & & Estrato & 12 & $0,004 *$ \\
\hline \multirow{3}{*}{ S } & Mes & 8,90 & $0,00010^{*}$ & \multirow{3}{*}{$\mathrm{NH}_{4}^{+}$} & Mes & 13 & $0,00010^{*}$ \\
\hline & Estación & 11 & $0,00010^{*}$ & & Estación & 5,60 & $0,00010^{*}$ \\
\hline & Estrato & 0,90 & $0,34 \mathrm{NS}$ & & Estrato & 0,96 & $0,33 \mathrm{NS}$ \\
\hline \multirow{3}{*}{ Sigmat } & Mes & 23 & $0,00010^{*}$ & \multirow{3}{*}{ NT } & Mes & 37 & $0,00010^{*}$ \\
\hline & Estación & 13 & $0,00010^{*}$ & & Estación & 2,30 & $0,0044^{*}$ \\
\hline & Estrato & 2,20 & $0,14 \mathrm{NS}$ & & Estrato & 0,96 & $0,33 \mathrm{NS}$ \\
\hline \multirow{3}{*}{$\mathrm{O}_{2}$} & Mes & 42 & $0,00010^{*}$ & \multirow{3}{*}{$\mathrm{PO}_{4}{ }^{3-}$} & Mes & 11 & $0,00010^{*}$ \\
\hline & Estación & 9,40 & $0,00010^{*}$ & & Estación & 1,7 & $0,06000^{*}$ \\
\hline & Estrato & 2,50 & $0,12 \mathrm{NS}$ & & Estrato & 2,20 & $0,14 \mathrm{NS}$ \\
\hline \multirow{3}{*}{$\mathrm{pH}$} & Mes & 196 & $0,00010^{*}$ & \multirow{3}{*}{ PT } & Mes & 11 & $0,00010^{*}$ \\
\hline & Estación & 32 & $0,00010^{*}$ & & Estación & 3,40 & $0,00010^{*}$ \\
\hline & Estrato & 17 & $0,00010^{*}$ & & Estrato & 0,43 & $0,051 \mathrm{NS}$ \\
\hline \multirow{3}{*}{$\mathrm{NO}_{3}^{-}$} & Mes & 18 & $0,00010^{*}$ & \multirow{3}{*}{ Chl $a$} & Mes & 8,3 & $0,00010^{*}$ \\
\hline & Estación & 1,70 & $0,00010^{*}$ & & Estación & 2,9 & $0,00030^{*}$ \\
\hline & Estrato & 8,70 & $0,0005^{*}$ & & Estrato & 2 & $0,16 \mathrm{NS}$ \\
\hline
\end{tabular}

$\mathrm{F}=$ estadístico de Fisher, $\mathrm{P}=$ nivel de significancia, $\mathrm{NS}=$ =no significativo, *=significativo

se observó un incremento en la celeridad, ubicándose los máximos entre marzo y abril cuando los valores excedieron los $4 \mathrm{~m} / \mathrm{s}$. Por otra parte la precipitación mostró un comportamiento contrario a la velocidad del viento. Los valores fluctuaron entre 0 (período de sequía) y $80 \mathrm{~mm}$ con un promedio de $21,5 \mathrm{~mm}$. Los máximos con valores superiores a $60 \mathrm{~mm}$, se ubicaron entre septiembre y octubre (Fig. 2B). Se determinaron temperaturas entre 22,10 y $31,60^{\circ} \mathrm{C}$ con un promedio de $25,69^{\circ} \mathrm{C}$ en las de superficie y entre 21,50 y $31,60{ }^{\circ} \mathrm{C}$ con promedio de $25,17^{\circ} \mathrm{C}$ en los registros de fondo. La distribución mensual de la temperatura en la columna de agua mostró dos importantes sucesos estacionales (Fig. 3A). Un período de aguas cálidas desde septiembre hasta noviembre de 1995 cuando los valores variaron entre 26,00 y $31,60{ }^{\circ} \mathrm{C}$ y un período de descenso gradual derivado del afloramiento de aguas más frías desde el fondo a la superficie (surgencia anemogénica), entre finales de diciembre 1995 hasta mayo de 1996, donde las temperaturas fueron mínimas $\left(21,50-22,10^{\circ} \mathrm{C}\right)$. Este patrón de distribución estuvo en concordancia con el observado en la celeridad de viento (Fig.2A). SiMPSON \& GRifFiths (1967) reportaron un estudio de la estructura térmica del golfo de Cariaco desde agosto de 1959 hasta agosto de 1961 e indicaron valores superiores a $27,91{ }^{\circ} \mathrm{C}$ durante septiembre y mínimos de $22,50{ }^{\circ} \mathrm{C}$ durante marzo, distribución que es concordante con lo observado en esta investigación. 
La salinidad superficial varió entre 14,750 y 37,180 unidades con promedio de 35,410 unidades en la superficie, mientras que en las aguas de fondo la variación fue entre 14,750 a 37,120 con promedio de 35,750 unidades. Los valores mínimos de salinidad fueron observados entre los meses de septiembre a diciembre (salinidades inferiores a 35 unidades). Los máximos fueron apreciados durante los primeros meses del año, concordante con los eventos de surgencia cuando los valores llegan a superar las 37,000 unidades (Fig.3B). Los mínimos valores fueron apreciados en las primeras estaciones ubicadas en el extremo más oriental del golfo, denominado saco del golfo. Esta zona está influenciada directamente con la descarga de las aguas del rio Carinicuao. En el sector oriental del golfo, las bajas salinidades estuvieron asociadas a las precipitaciones (Fig.2B) y al aporte de agua dulce del rio Carinicuao. Según Febres (1974), Caraballo (1982), Márquez et al. (2005) y Quintero et al. (2006) en el golfo desembocan 34 cursos
$3 \mathrm{~A}$

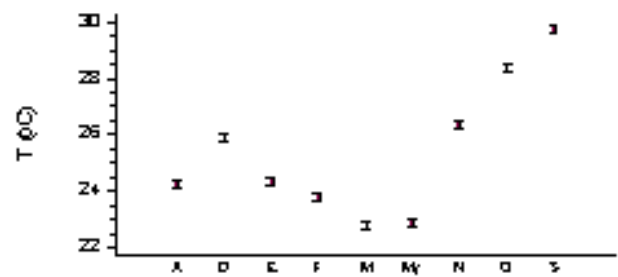

$3 \mathrm{C}$

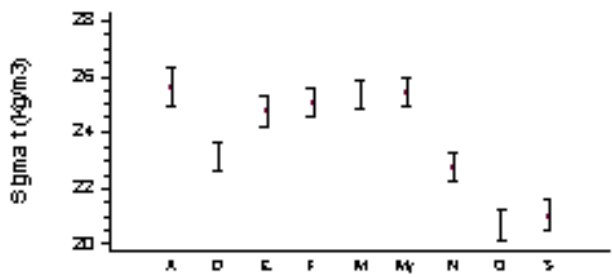

$3 \mathrm{E}$

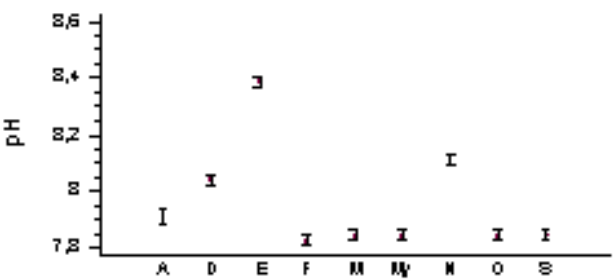

$3 \mathrm{~B}$

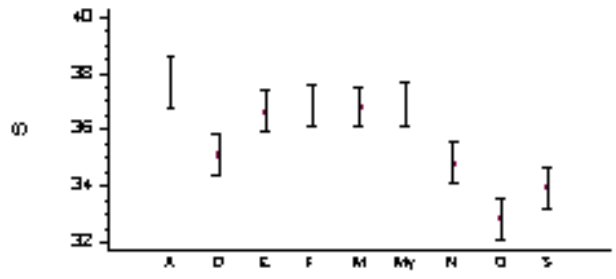

$3 \mathrm{D}$

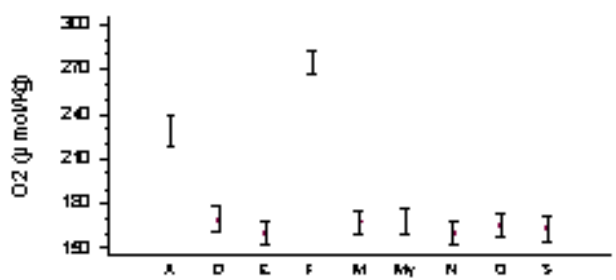

$3 \mathrm{~F}$

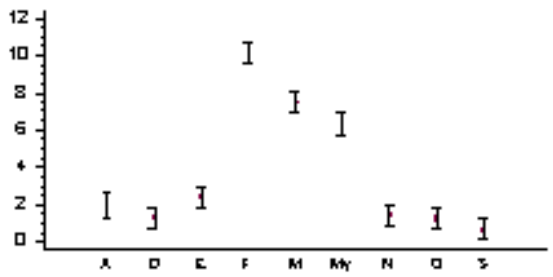

Fig.3. Valores promedios mensuales para los parámetros, temperatura, salinidad, oxígeno disuelto, densidad (sigma t), pH, especies oxidadas y reducidas de nitrógeno, nitrógeno total, fosfato, fosforo total y clorofila $a$ en aguas del sector oriental del golfo de Cariaco. 
de agua, en la costa sur y representan los mayores caudales, mientras que en la costa norte lo hacen 45 , pero con caudales reducidos y de muy corto recorrido. Tienen poca influencia sobre la hidrología del golfo de Cariaco, pues de los mayores, el aporte del río Cariaco ha disminuido en los últimos años, debido a la deforestación y al uso agrícola. Por otra parte, el río Manzanares desemboca fuera del golfo, desviándose hacia el oeste. Se ha observado otra

$3 \mathrm{G}$

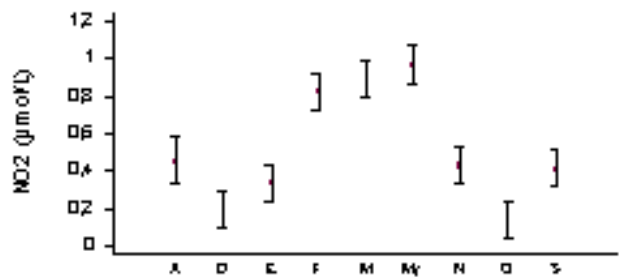

$3 \mathrm{I}$

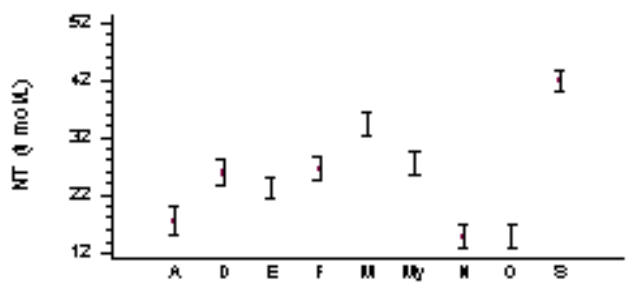

$3 \mathrm{~K}$

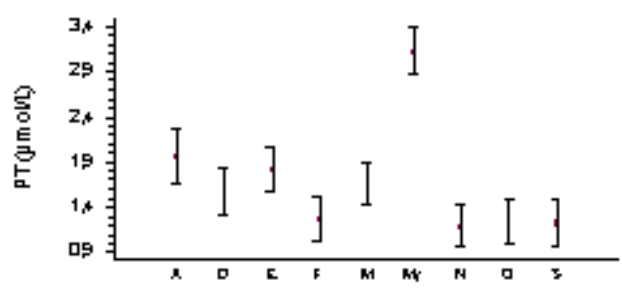

tendencia que depende de la dirección de la corriente de marea. En ellas encuentra un flujo hacia el nor-noreste, del cual se desconoce si afecta el sector Oriental del golfo (Com. personal. Dr. Julían CASTAÑEDA, I.O.V, Universidad de Oriente). Es por ello que se asume que la mayor contribución en el lado este es debido al río Carinicuao (Márquez et al. 2005). Según Benítez (1974), las salinidades superficiales dentro del golfo de Cariaco varían

$3 \mathrm{H}$

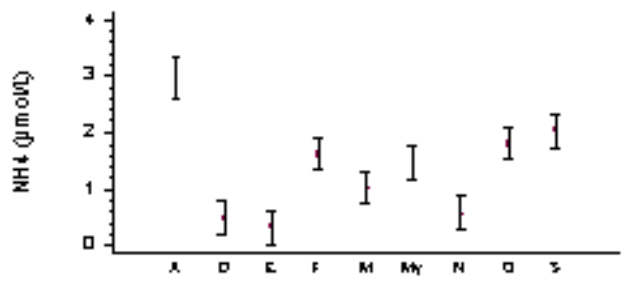

$3 \mathrm{~J}$

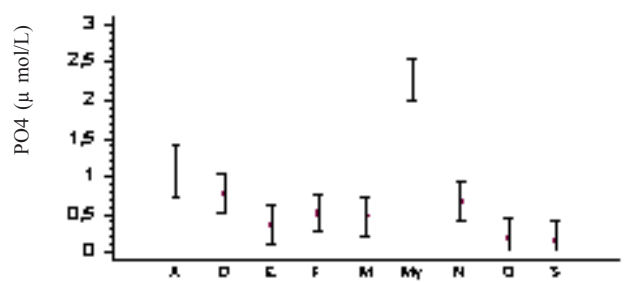

$3 \mathrm{~L}$

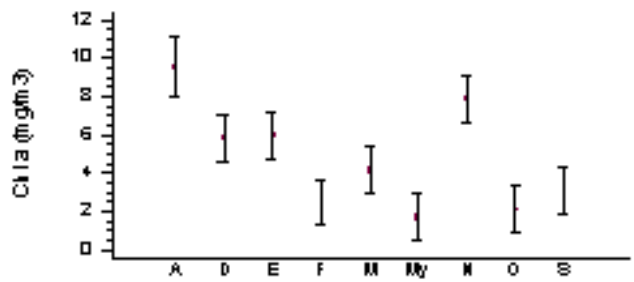

Continuación de Fig.3. (Valores promedios mensuales para los parámetros, temperatura, salinidad, oxígeno disuelto, densidad (sigma t), pH, especies oxidadas y reducidas de nitrógeno, nitrógeno total, fosfato, fosforo total y clorofila $a$ en aguas del sector oriental del golfo de Cariaco). 
entre 36,60 y 36,80 y mínimos de 26,29 . Si se consideran estos valores es de sugerir que las salinidades, dentro en los últimos 30 años, se han mantenido con poca variación. Esta observación se corroboró con los valores obtenidos en esta investigación, los cuales mostraron valores máximos de 37,18 unidades con promedio de 35,41 unidades en la superficie.

La anomalía de densidad (Sigma-t), osciló entre 7,48 a $25,62 \mathrm{~kg} / \mathrm{m}^{3}$ con promedio de $23,43 \mathrm{~kg} / \mathrm{m}^{3}$ en las aguas de superficie, mostrando poca variabilidad hacia el fondo de la columna, donde los valores oscilaron entre 7,48 hasta 25,87 $\mathrm{kg} / \mathrm{m}^{3}$ con un promedio de $23,84 \mathrm{~kg} / \mathrm{m}^{3}$ (Tabla 2, Fig. 3C). La distribución temporal de la densidad mostró un patrón de distribución similar al de la salinidad e inverso al de la temperatura. Los valores mínimos de densidad coinciden con los de salinidad y con los de máximas temperaturas, lo cual sugiere que, el grado de insolación y el aporte de agua dulce son los principales factores que determinan el campo de densidad del agua dentro del golfo de Cariaco.

La concentración de oxígeno disuelto varió entre 76,35 a $346,18 \mu \mathrm{mol} / \mathrm{kg}$ con promedio de 184,49 en superficie y entre 76,35 a $363,82 \mu \mathrm{mol} / \mathrm{kg}$ con media de $178,38 \mu \mathrm{mol} / \mathrm{kg}$ en el fondo. La distribución temporal se caracterizó por un patrón de poca variación entre los meses. El promedio estuvo por debajo de los $185 \mu \mathrm{mol} / \mathrm{kg}$, a excepción de febrero y abril cuando los valores superaron los $200 \mu \mathrm{mol} /$ $\mathrm{kg}$ (Fig. 3D). Este patrón de distribución hace suponer que los máximos en estos dos meses pudieran estar asociados con procesos de intercambio atmosfera- océano, debido la mayor intensidad de los vientos para ese lapso, ya que no se observó asociación con la intensidad de la actividad fotosintética, cuantificada esta última a través de las concentraciones de clorofila $a$. Los valores de $\mathrm{pH}$ en superficie y fondo variaron entre 7,45 y 8,53 y entre 7,45 a 8,45 unidades, respectivamente. Los promedios fueron para ambos casos 7,98 y 7,94. Durante casi todo el estudio los valores fueron inferiores a las 8 unidades con excepción de los meses de noviembre, diciembre y enero (Fig. 3E). Esta distribución sugiere que el material orgánico formado por los productores primarios durante el período de surgencia, aporta nutrientes a las aguas de superficie. La materia orgánica es degradada in situ por las bacterias que toman el oxígeno como aceptor de electrones para respirar el material orgánico y bajan el pH (LiBES 1992).

Las concentraciones de los nutrientes nitrogenados y fosforados en superficie variaron entre ND y $11,89 \mu \mathrm{mol} / \mathrm{L}$ con promedio de $3,18 \mu \mathrm{mol} / \mathrm{L}$ y ND a $19,47 \mu \mathrm{mol} / \mathrm{L}$ con promedio de $4,22 \mu \mathrm{mol} / \mathrm{L}$ en superficie y fondo para nitrato, mientras que para nitrito la variación fue de 0,01 a 2,02 $\mu \mathrm{mol} / \mathrm{L}$ con valor intermedio de $0,45 \mu \mathrm{mol} / \mathrm{L}$ y 0,01 a 2,51 $\mu \mathrm{mol} / \mathrm{L}$ con promedio de $0,60 \mu \mathrm{mol} / \mathrm{L}$ para superficie y fondo. La especie más reducida del nitrógeno representada por el amonio osciló entre ND a $8,13 \mu \mathrm{mol} / \mathrm{L}$ y promedio de 1,25 $\mu \mathrm{mol} / \mathrm{L}$ para las aguas de superficie y de ND a $8,05 \mu \mathrm{mol} / \mathrm{L}$ con media de 1,39 $\mu \mathrm{mol} / \mathrm{L}$ para las aguas de fondo. Las concentraciones del nitrógeno total a su vez fueron de 4,75 a $86 \mu \mathrm{mol} / \mathrm{L}$ con promedio de $25,28 \mu \mathrm{mol} / \mathrm{L}$ en el estrato superficial, mientras que en el fondo los valores variaron de 9,25 a $90 \mu \mathrm{mol} / \mathrm{L}$ con promedio de $26,31 \mu \mathrm{mol} / \mathrm{L}$ (Tabla 2).

La distribución de las especies oxidadas del nitrógeno mostraron sus máximos durante febrero, marzo y mayo cuando los valores superaron los 8 $\mu \mathrm{mol} / \mathrm{L}$ (Fig.3F). Situación similar fue observada para las concentraciones de nitrito, las cuales mostraron

Tabla 2. Valores mínimos, máximos y promedios de los diferentes parámetros evaluados en las aguas de superficie y fondo en el sector oriental del golfo de Cariaco, estado Sucre, Venezuela.

\begin{tabular}{|c|c|c|c|c|c|c|c|c|c|c|c|c|c|c|}
\hline \multicolumn{15}{|c|}{ Superficie } \\
\hline & $\begin{array}{c}\mathrm{T} \\
(\mathrm{C})\end{array}$ & $\mathrm{pH}$ & $\mathrm{s}$ & $\begin{array}{c}02 \\
(\mu \mathrm{mol} / \mathrm{Kg})\end{array}$ & $\begin{array}{c}\mathrm{UAO} \\
(\mu \mathrm{mol} / \mathrm{Kg})\end{array}$ & $\begin{array}{l}\text { Sigma t } \\
\left(\mathrm{Kg} \mathrm{m}^{\prime}\right)\end{array}$ & $\begin{array}{l}\mathrm{HH}_{4}{ }^{\circ} \\
(\mathrm{moll})\end{array}$ & $\begin{array}{c}\mathrm{HO}_{2}^{-} \\
(\mathrm{mol} / \mathrm{L})-\end{array}$ & $\begin{array}{c}\mathrm{HO}_{3}^{-} \\
(\mathrm{mol})\end{array}$ & $\begin{array}{c}\mathrm{HT} \\
(m \mathrm{NL})\end{array}$ & $\begin{array}{c}\mathrm{PO}_{4}^{3} \\
(\mathrm{~mol} / \mathrm{L})\end{array}$ & $\begin{array}{c}\text { PT } \\
\text { (moll })\end{array}$ & $\begin{array}{c}\text { Chl } a \\
(\operatorname{mgh} 3)\end{array}$ & $\begin{array}{c}\text { Nstar } \\
(\operatorname{molKg})\end{array}$ \\
\hline $\mathbf{M n}$ & 22,10 & 7,45 & 14,75 & 76355 & $-141,69$ & 7,48 & 0,00 & 0,01 & 0 & 475 & 0,01 & 027 & 0,00 & $-124,04$ \\
\hline $\operatorname{Max}$ & $31 £ 0$ & 8,53 & 37,18 & 346,18 & 140,35 & 25,62 & 8,13 & $2 \rho_{2}$ & 1189 & $86 \rho 0$ & 9,12 & $9 \rho 9$ & 38,50 & 975 \\
\hline Prom & $25 \$ 9$ & 798 & 35,41 & 184,49 & 19,87 & 23,43 & $\begin{array}{l}125 \\
\text { Fondo }\end{array}$ & 0,45 & 3,18 & 25,28 & $0 f 0$ & 1,63 & 5,19 & $-3,02$ \\
\hline $\mathbf{M i n}$ & 21,50 & 7,45 & 14,75 & 7635 & $-156,84$ & 7,48 & 0,00 & 0,01 & 0 & 9,25 & ND & 0,16 & 0,00 & -131 \\
\hline $\operatorname{Max}$ & $31 \wp 0$ & 8,45 & 37,12 & $363 \not 22$ & 140,31 & 25,87 & 8,05 & 2,51 & 19,47 & $90 \rho 0$ & 10,81 & $9 \rho 9$ & 2729 & 9,63 \\
\hline Prom & $25 \$ 9$ & 794 & 3575 & 178,38 & 27,47 & 23,84 & 139 & $0 \rho 0$ & 422 & 26,31 & 079 & 1,70 & 4,33 & $-4,82$ \\
\hline
\end{tabular}


incrementos con los descensos en las concentraciones de nitrato debido a procesos de denitrificación (Fig.3G). La distribución temporal de las concentraciones amonio (Fig. $3 \mathrm{H})$ muestra un patrón diferente al observado en las especies oxidadas. Las concentraciones promedios máximas, las cuales son cercanas a $3 \mu \mathrm{mol} / \mathrm{L}$ se determinaron durante abril, y las mínimas, las cuales estuvieron por debajo de $1 \mu \mathrm{mol} / \mathrm{L}$, se observaron en diciembre, enero y febrero. Los otros meses presentaron valores intermedios a los apreciados en diciembre, enero, febrero y abril. La distribución temporal de las concentraciones del nitrógeno total (Fig. 3I) no muestra un patrón concordante con las especies oxidadas del nitrógeno, especialmente para los meses de febrero, marzo y mayo, meses incluidos en el período de surgencia. Las concentraciones de las especies fosfatadas fluctuaron entre 0,01 a $9,12 \mu \mathrm{mol} / \mathrm{L}$ con promedio de $0,60 \mu \mathrm{mol} / \mathrm{L}$ para los fosfatos en superficie y de ND a $10,81 \mu \mathrm{mol} / \mathrm{L}$ con media de $0,79 \mu \mathrm{mol} / \mathrm{L}$ en el fondo. Por otra parte, los valores de fósforo total (PT) variaron entre $0,27 \mu \mathrm{mol} / \mathrm{L} \mathrm{a} 9,09 \mu \mathrm{mol} /$ $\mathrm{L}$ en superficie y de $0,16 \mu \mathrm{mol} / \mathrm{L}$ a $9,09 \mu \mathrm{mol} / \mathrm{L}$ en el fondo (Tabla 2). Los máximos valores para fosfatos y fósforo total fueron observados durante los meses iniciales del año, especialmente para el mes de mayo (Fig. 3J y Fig. 3K).

Las concentraciones de clorofila $a(\mathrm{Chl}-a)$ fluctuaron entre ND a $38,50 \mathrm{mg} / \mathrm{m}^{3}$ en superficie y de ND a $27,29 \mathrm{mg} /$ $\mathrm{m}^{3}$ en el fondo. Los promedios en ambos casos fueron de $5,19 \mathrm{mg} / \mathrm{m}^{3}$ y $4,33 \mathrm{mg} / \mathrm{m}^{3}$, respectivamente (Tabla 2). Se apreció un desfase temporal de la clorofila $a$ durante el estudio (Fig.3L), esto debido a que, las concentraciones máximas no coincidieron precisamente con los máximos de nutrientes. Esta observación es contrastante con lo reportado por RICHARD (1963), el cual estudió por primera vez las características hidrográficas e hidroquímicas del golfo de Cariaco, e indicó que la surgencia es la principal fuente de nutrientes a la zona eufótica, lo que esto explicaria la alta productividad biológica del golfo de Cariaco. Igual conjetura fue confirmada por MARGALEF (1965), quien consideró al golfo de Cariaco como una de las áreas de surgencia más productiva de la zona nororiental de Venezuela. Este fenómeno de altas concentraciones de nutrientes baja clorofila (HNLC) ocurre porque el fitoplancton reciente presenta inconvenientes de aclimatación (Sото 2011).

Las condiciones meteorológicas en la región nororiental de Venezuela tienen un fuerte impacto sobre las características hidrográficas del golfo de Cariaco, en especial en los procesos físicos de evaporación, afloramiento y circulación superficial de las aguas, tal como lo han señalado Febres-ORTEGA (1974). OKUDA (1982), Muller-Karger \& APARicio (1994) y Astor et al. (2003), indicando que la surgencia observada en las costas centrales y orientales de Venezuela es debida a la intensidad de los vientos alisios los cuales soplan en direcciones noroeste. Este afloramiento llevan las aguas de bajas temperaturas a la superficie. Esta observación fue corroborada con lo observado en la figura 2 y figura 4. Cuando ocurren estos eventos, los materiales sedimentados en el fondo (nitratos, nitritos, fosfatos) se ponen en circulación hacia las capas más superficiales de agua por lo cual pueden ser aprovechados por los organismos planctónicos allí presentes, mejorando en gran medida la cadena alimenticia marina (CONEJEROS, 1986). Tal situación se ve reflejada en los resultados obtenidos en la presente investigación.

El comportamiento global de las aguas del golfo de Cariaco durante el período de surgencia costera y su relajación son mostrados en la figura 4. Durante la surgencia, (Fig.4A) las aguas presentaron valores por debajo de $25,00{ }^{\circ} \mathrm{C}$ y un patrón de mezcla vertical y horizontal en el interior del golfo. Las isotermas inferiores a $25,00{ }^{\circ} \mathrm{C}$ penetraron hasta la parte más oriental, mientras que durante la relajación el patrón fue similar pero con temperaturas superiores a $27,00^{\circ} \mathrm{C}$ (Fig.4B). La salinidad, igualmente muestra un patrón de mezcla vertical homogéneo durante la surgencia, asociada con salinidades superiores a 32,000 unidades; sin embargo, durante la relajación hubo un descenso de los valores hacia el extremo más oriental del Golfo. Estos declives están en concordancia con el incremento en la precipitación (Fig.2B) y a la mayor descarga del rio Carinicuao por incremento de su caudal. Las isohalinas inferiores a 32 unidades no se desplazan hacia el extremo más occidental debido a la escasa circulación y la topografía más somera que presenta el borde más oriental del golfo.

La densidad mostró un patrón similar a la salinidad. Estuvo influida por la temperatura en el período de surgencia (Fig.4E) y por el aporte de agua fluvial y mayor precipitación durante el evento de relajación (Fig.4F). Ferraz (1989) y SiMPSON \& GRIFFITHS (1971) han señalado que el intercambio de las aguas del golfo de Cariaco con el exterior no es continuo, por tanto, el tiempo de residencia de las aguas del golfo de Cariaco es prolongado, ya que la tasa de renovación varía estacionalmente con el régimen de vientos. 

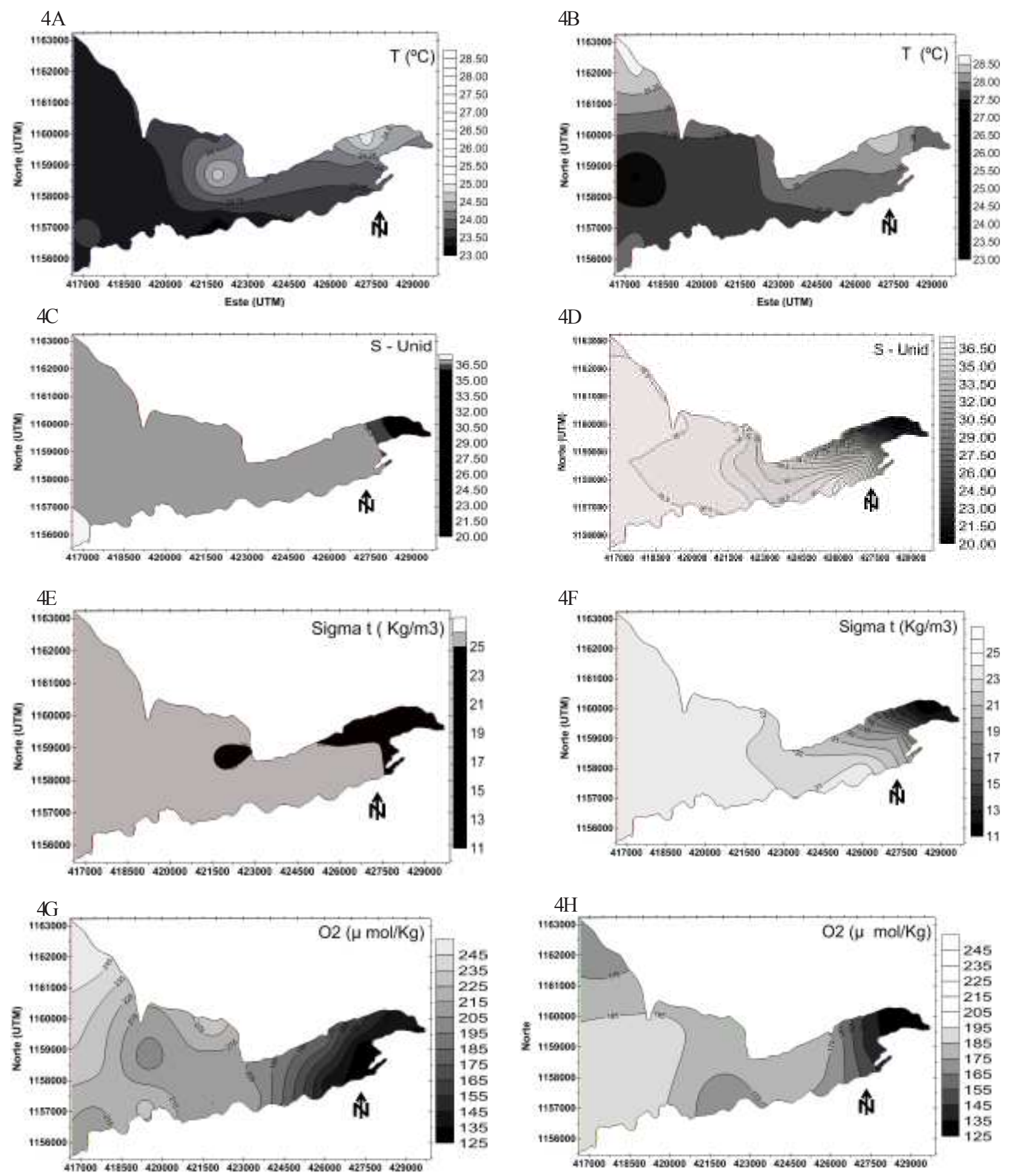

Fig. 4. Distribución espacial de las variables temperatura (A,B), salinidad (C,D), densidad (E,F) oxígeno disuelto (G,H), utilización aparente de oxígeno $(\mathrm{I}, \mathrm{J}), \mathrm{pH}(\mathrm{K}, \mathrm{L})$, amonio $(\mathrm{M}, \mathrm{N})$ y nitrato $(\mathrm{O}, \mathrm{P})$, nitrito $(\mathrm{Q}, \mathrm{R})$, denitrificación $(\mathrm{S}, \mathrm{T})$, nitrógeno total $(\mathrm{U}, \mathrm{V})$, fosfato $(\mathrm{W}, \mathrm{X})$, y fósforo total $(\mathrm{Y}, \mathrm{Z})$ en aguas superficiales del sector oriental del golfo de Cariaco durante surgencia y relajación. 
El sector oriental del golfo de Cariaco, Venezuela
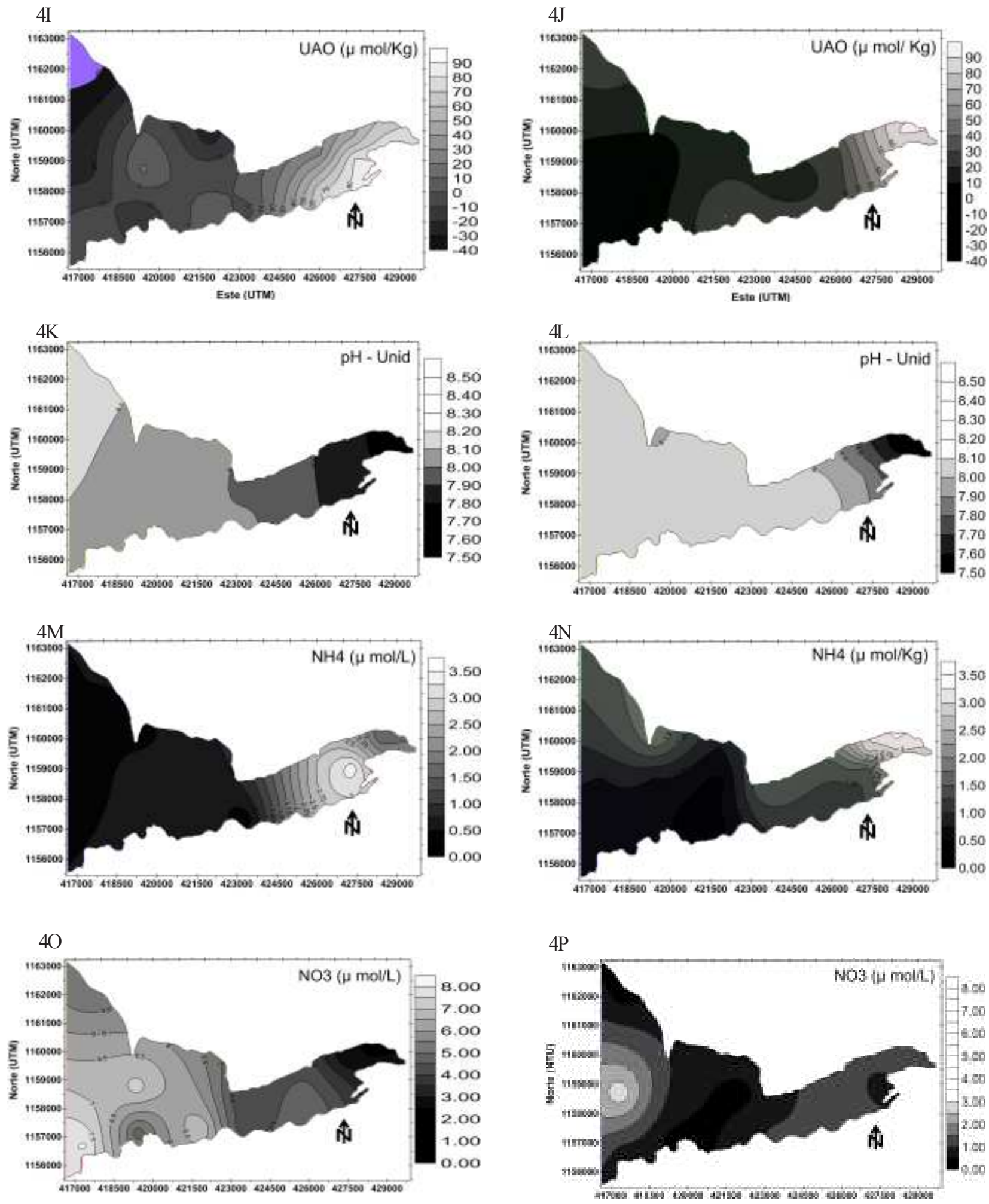

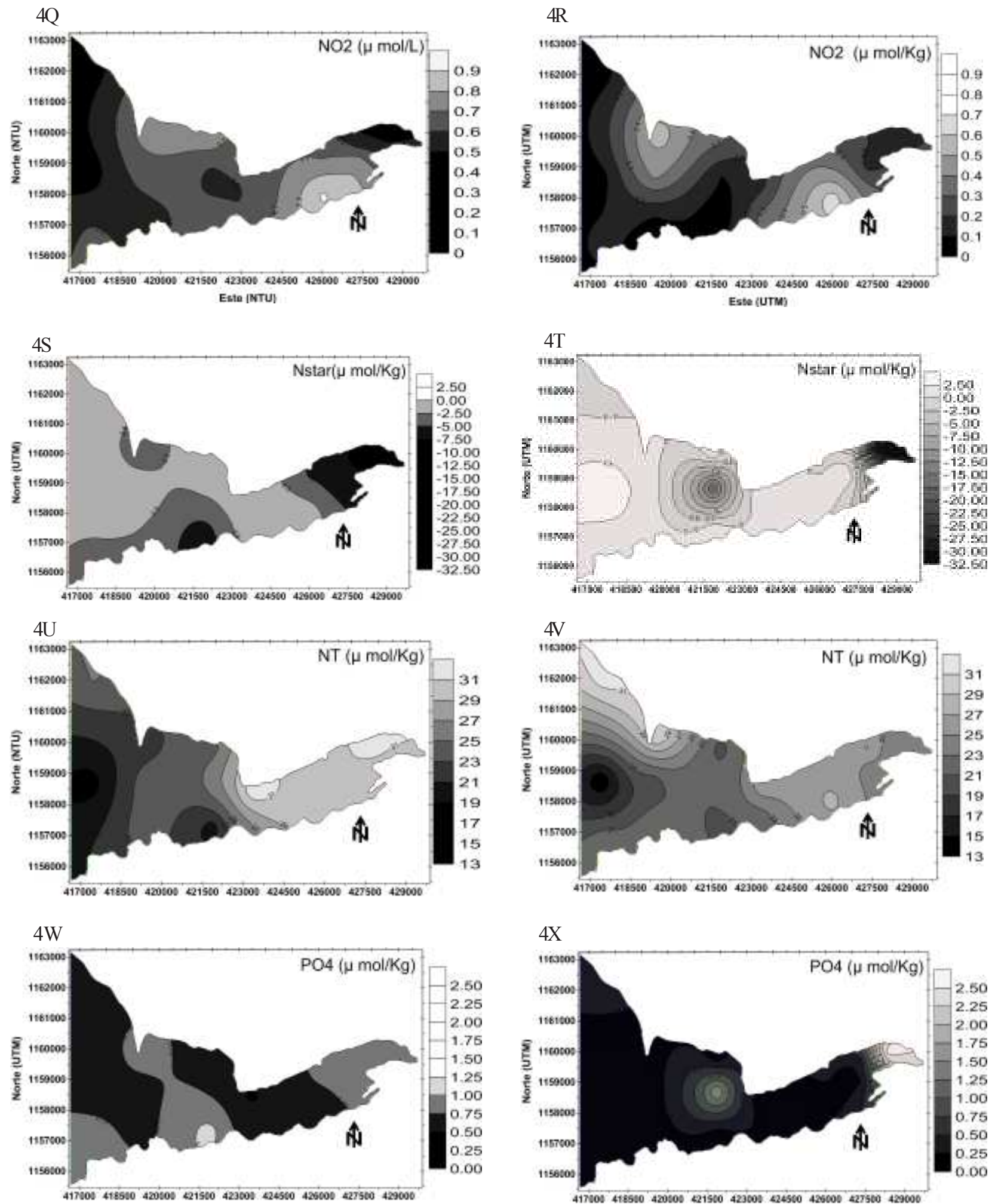


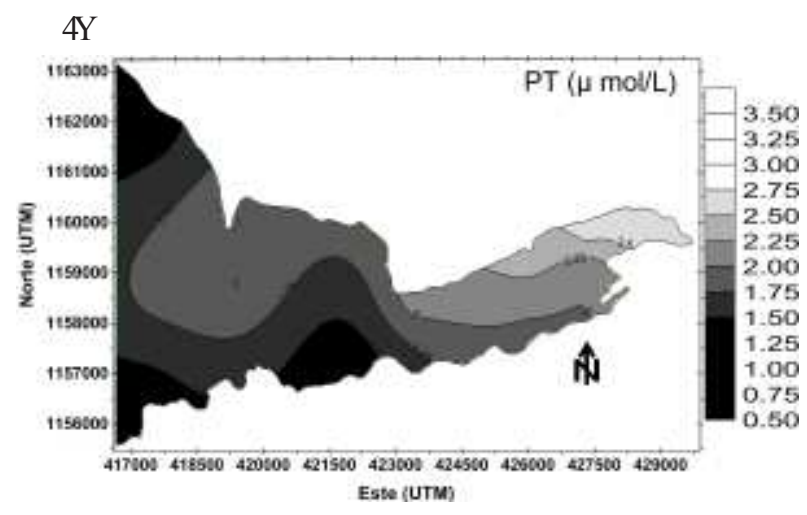

Las concentraciones de oxígeno disuelto, por otra parte, fueron mayores durante surgencia (Fig.4G) que en la relajación (Fig.4H). La distribución mostró sus valores más bajos hacia el extremo oriental del saco. Las menores concentraciones durante el período de aguas más cálidas están asociadas a la perdida de solubilidad del oxígeno con la elevación de la temperatura, también a la degradación de material orgánico, mecanismo en el cual las bacterias utilizan el oxígeno como aceptor de electrones (Libes 1992). Estas observaciones son corroboradas con los valores altos apreciados en la utilización aparente de oxígeno los cuales superaron los $50 \mu \mathrm{mol} / \mathrm{kg}$ de (Fig.4I, Fig.4J). De igual manera, las figuras 4I y $4 \mathrm{~J}$ muestran que, durante la surgencia, se evidenciaron procesos fotosintéticos (valores negativos de UAO) hacia el extremo occidental de la zona de estudio (Fig.4I). Durante la relajación de la surgencia (Fig.4J), estos procesos disminuyeron y se incrementó la degradación de la materia orgánica del material acumulado durante el período de surgencia, además del material proveniente de la descarga fluvial en la zona. Esta última situación fue corroborada por la posición en la isopigna de $25 \mathrm{~kg} / \mathrm{m}^{3}$. Los procesos degradativos observados fueron corroborados con las observaciones que mostraron los descensos del pH (Fig.4k y Fig.4L), al igual con el incremento de las concentraciones de amonio (Fig.4M y Fig.4N).

Durante la surgencia hubo un incremento de nitrato en las aguas occidentales del saco (Fig.4O) y descensos hacia el extremo oriental del saco. La última situación se hizo más crítica durante la relajación (Fig.4P) cuando los valores decayeron por debajo de $2 \mu \mathrm{mol} / \mathrm{l}$ en casi toda la zona. En surgencia y relajación se determinó un incremento en los valores de nitrito (Fig.4Q) concordante con los descensos de nitrato. Esta observación sugiere que existen

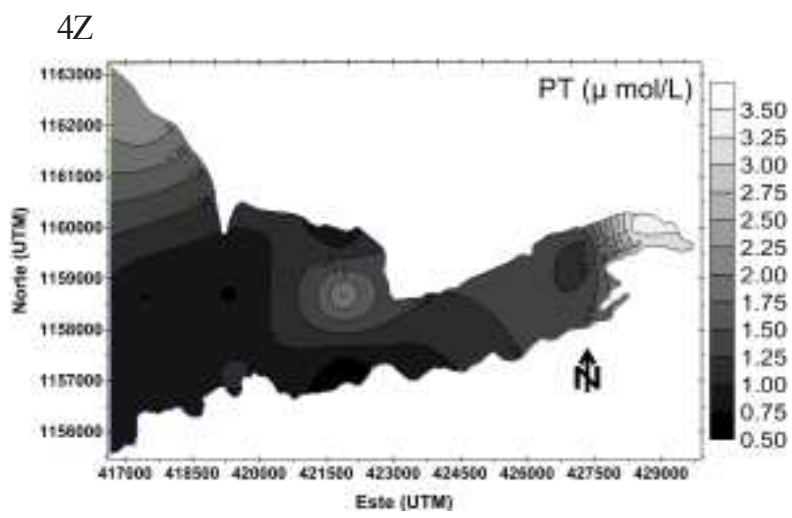

mecanismos de denitrificación que están asociados con la reducción de las especies oxidadas e incremento en las especies reducidas del nitrógeno, tal como se observa en las figuras $4 \mathrm{M}$ y $4 \mathrm{~N}$. Estos eventos de denitrificación fueron confirmados con los valores negativos de $\mathrm{N}^{*}$ (Nstar, Fig.4S, Fig. 4T). Este mecanismo es más constante en toda el área, especialmente en la isopigna de 25 durante la surgencia, pero más intenso en magnitud durante la relajación, especialmente en el extremo más oriental cuando las aguas están más cálidas y los niveles de oxígeno más bajas (Fig.4H).

Los valores de nitrógeno total fueron mayores hacia el interior del saco del golfo durante la surgencia (Fig.4 U). Un caso contrario se observó durante el cese de la surgencia (Fig.4V). Por otra parte durante los dos eventos, las concentraciones de fosfato y fósforo total mostraron una distribución similar especialmente hacia el extremo oriental del saco (Fig.4W y Fig.4X). Los valores más elevados hacia el borde oriental podrían estar asociados a procesos de degradación de materia orgánica, $\mathrm{y} / \mathrm{o}$ aportes desde las aguas cargadas en fertilizantes que provienen del río Carinicuao, tal como lo ha señalado MÁrQuez et al. (2005). Para las concentraciones del fósforo total, la distribución está asociada al aporte de los fosfatos, y posiblemente al aporte de fósforo orgánico (Fig.4Y y Fig.4Z).

Durante el período de surgencia se determinó que la relación Redfield fue $\mathrm{N}: \mathrm{P}=16: 1$. Esta se incrementó a N:P $=24: 1$ durante el período de relajación debido al incremento de las concentraciones de amonio. Por otra parte, la clorofila $a$ mostró un desfase con los nutrientes, especialmente durante la surgencia. Los máximos no coincidieron con los de nutrientes. Durante los meses de 
surgencia (Fig.5A), las mayores concentraciones se ubicaron en el extremo norte del golfo, sector noroccidental y en el extremo oriental, mientras que durante el cese de la surgencia los máximos están desplazados hacia el extremo suroriental. Este comportamiento evidencia que el fitoplancton no responde en forma directa al incremento de los nutrientes. La dinámica del fitoplancton y de la clorofila $a$ está determinada por los factores físicos que varían de región a región, la topografía, y entre estaciones climáticas. Los factores que afectan son principalmente la biomasa autotrófica por sí misma, la radiación solar, temperatura, concentración de nutrientes, los metales trazas disponibles, historia de vida y distribución taxonómica del fitoplancton (Platt \& Sathyendranath 1999). Dentro de este contexto físico hay que considerar los procesos horizontales y verticales, el viento como fuente de mezcla y trasporte vertical de nutrientes, la advección horizontal y radiación solar (ESPINOZA-CARREÓN \& VAldeZ-Holguin 2007). En la Tabla III se muestra una breve comparación entre los resultados obtenidos en esta investigación y otros sitios de importancia en Venezuela y
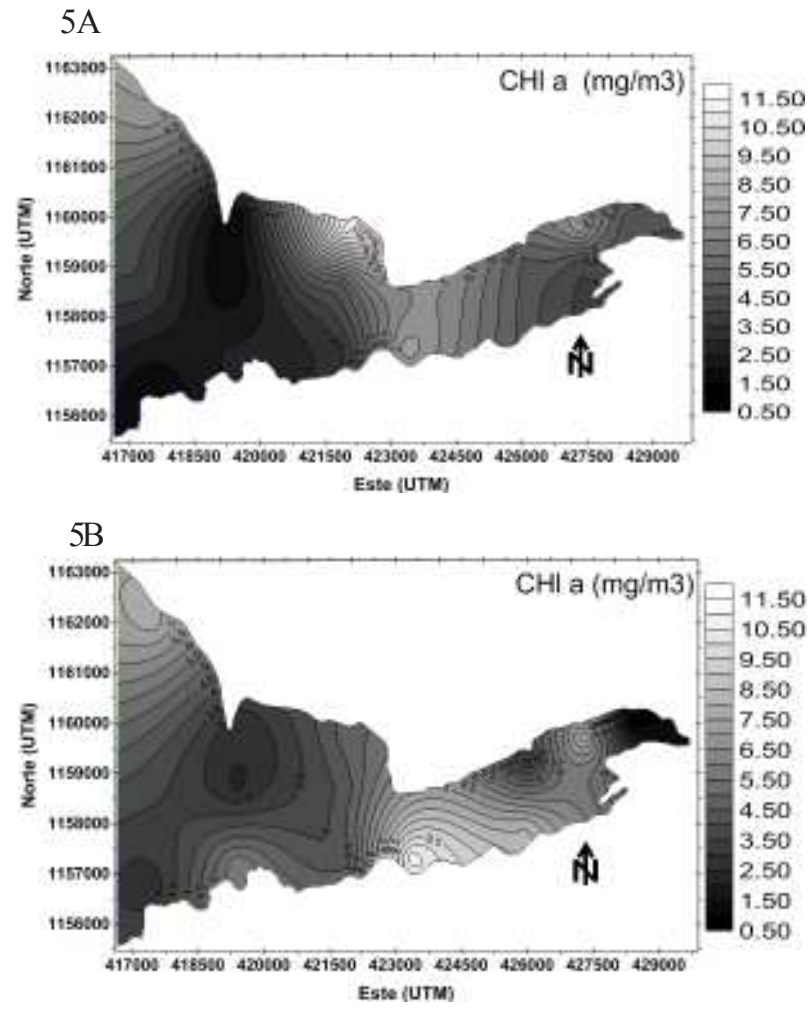

Fig.5. Distribución espacial de las concentraciones de clorofila $a$ en aguas superficiales del sector oriental del golfo de Cariaco durante surgencia y relajación a nivel mundial. Todos estos sitios están influenciados por eventos de surgencia; sin embargo, la comparación muestra que el golfo de Cariaco representa un sector de mayor fertilidad y producción primaria, corroborando las observaciones de algunos autores que ya han sido citados en la presente investigación.

El análisis de factores aplicado a las variables hidroquímicas, en función de los componentes principales, muestra que los tres primeros componentes explican el $81,91 \%$ de las diferentes variables estudiadas en el sector oriental del golfo de Cariaco (Tabla.IV). En la figura 6 se observa, que las variables físico-químicas, temperatura, $\mathrm{pH}$, salinidad y Sigma T, al igual que el amonio dominan el componente uno, este primer componente es el de mayor variancia $(39,59 \%)$, siendo el de mayor peso para explicar la totalidad de las variables estudiadas, señalando aguas cálidas, menos salinas y ricas en amonio, evidenciándose esto por la correlación negativa existente entre la temperatura con las variables, $\mathrm{pH}$, salinidad y sigma $\mathrm{T}, \mathrm{y}$ la correlación positiva de este mismo parámetro con el amonio; este comportamiento podría estar influenciado por la descarga de ríos, riachuelos y aguas domésticas en zonas cercanas al área de estudio, especialmente el rio Carinicuao que es el cuerpo fluvial de mayor aporte. Así mismo, la asociación de estas variables físicoquímicas a un mismo componente demuestra que son influenciables por los mismos procesos, como es el caso de la surgencia costera que ha sido estudiada en esta zona. La concentración de oxígeno disuelto, la utilización aparente del oxígeno (UAO) y la clorofila $a$, dominan el componente 2 , el cual tiene una variancia explicativa de $25,04 \%$, con una correlación negativa entre el oxígeno y la UAO, indicando que este componente está estrechamente relacionado con

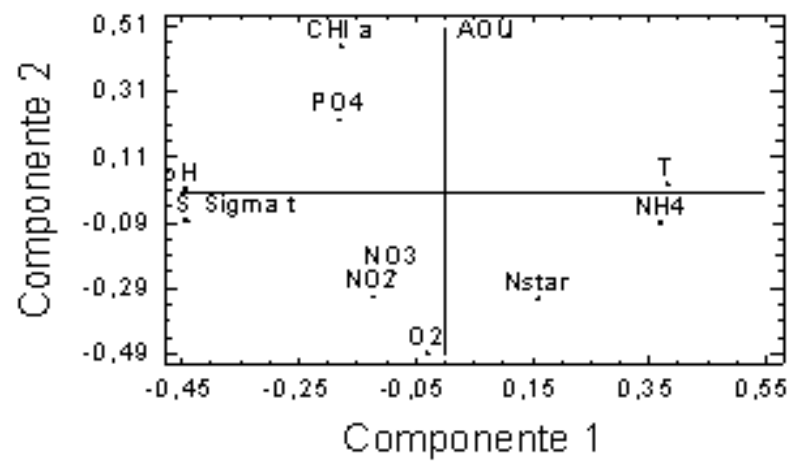

Fig. 6. Representación grafica de los dos primeros componentes principales para las variable hidroquímicas de las aguas del sector oriental del golfo de Cariaco 
El sector oriental del golfo de Cariaco, Venezuela

TABLA 3. Cuadro comparativo de las variables hidroquímicas en aguas marinas influenciadas por surgencia en de algunos sectores venezolanos y a nivel mundial

\begin{tabular}{|c|c|c|c|c|c|c|c|c|c|c|c|c|c|}
\hline $\mathrm{T}$ & $S$ & $\mathrm{O}_{2}$ & $\mathrm{pH}$ & $\mathrm{HO}_{3}^{\circ}$ & $\mathrm{HO}_{2}$ & $\begin{array}{l}\mathrm{HO}_{3}^{-} \\
+\mathrm{HO}_{2}^{-}\end{array}$ & $\mathrm{NH}_{4}{ }^{\circ}$ & $\mathrm{HT}$ & $\mathrm{PO}_{4}^{3-}$ & PT & Chl- $a$ & Localidad & Referencias \\
\hline 28,5 & 22,3 & 4,75 & 8,45 & 1,55 & 0,10 & & 1,1 & 15 & 0,20 & 0,50 & & Superficie & \\
\hline \multirow[t]{2}{*}{27,85} & 29,1 & 3,65 & 8,3 & 1,55 & 0,45 & & 1,25 & 14 & 0,25 & 0,70 & & Fondo & 1 \\
\hline & & & & & & & & & & & $=2,40 \mathrm{mg} / \mathrm{m}^{3}$ & & \\
\hline \multirow[t]{4}{*}{20} & 35,09 & & 8,16 & & & 2,35 & 2 & & & & & & 2 \\
\hline & & & & & & & & & & & $<2$ & $\begin{array}{l}\text { Golfo de } \\
\text { Califomia }\end{array}$ & 3 \\
\hline & & & & & & & & & & & $=2,40 \mathrm{mg} / \mathrm{m}^{3}$ & Golfo de Cariaco & 4 \\
\hline & 37,07 & 4,55 & & & 0,16 & & 8,29 & 24 & 0,37 & & & $\begin{array}{l}\text { Barriade } \\
\text { Mochima y } \\
\text { adyacencias de la } \\
\text { Fosa de Cariaco }\end{array}$ & 5 \\
\hline 25,69 & 35,41 & 4,10 & 7,98 & 3,18 & 0,45 & & 1,25 & 25,28 & 0,60 & 1,63 & 5,19 & Presente estudio & Superficie \\
\hline 25,17 & 35,75 & 4,90 & 7,94 & 4,22 & 0,60 & & 1,39 & 26,31 & 0,79 & 1,70 & 4,33 & & Fondo \\
\hline
\end{tabular}

1.- Martin et al.2007; 2.- Bustos-Serrano \& Castro Valdez, 2006; 3.- Espinoza-Carreón \& VÁzQuez- Holguín, 2007; 4.- Valera et al. 2003; 5.- Bonilla et al. 2003.

las actividades "in situ" de fotosíntesis y respiración principalmente. Los nutrientes principales, por su parte, dominan el componente 3 , aun cuando el nitrito $\left(\mathrm{NO}_{2}\right)$, nitrato $\left(\mathrm{NO}_{3}\right)$ y el proceso de desnitrificación (Nstar), también tienen un importante aporte en el componente 2, debido principalmente a sus importantes correlaciones con el oxígeno disuelto y la UAO. El componente 3 nos indica una entrada y fuente común para los nutrientes, evidenciado por las correlaciones positivas existentes entre ellos, que podrían estar representadas por las descargas de aguas servidas, sin ningún tratamiento previo, así como también, las aguas de escorrentías, riachuelos y ríos, especialmente el río Carinicuao que es el de mayor influencia en el área de estudio. Este último trae consigo los productos del lavado de suelos mayoritariamente agrícolas. Otra correlación que cabe destacar, es la registrada entre la clorofila $a$ y los nutrientes nitrogenados, correlación negativa que nos indica que, probablemente, pudieran ser estos nutrientes los que juegue un papel predominante en la nutrición del fitoplancton e incremento de la concentración de la clorofila $a$, especialmente durante los eventos de surgencia costera.

\section{CONCLUSIONES}

Las aguas del sector oriental del gofo de Cariaco no muestran diferencias significativas entre el estrato de superficie y el fondo; sin embargo hay variaciones en toda la columna en los diferentes meses del año y en las estaciones muestreadas. Esta diferencia es producida por efecto de la variación de la intensidad del viento en la zona nororiental de Venezuela que durante los primeros meses del año produce un afloramiento de guas frías que mezclan toda la columna de agua e incrementan las concentraciones de los nutrientes en la superficie.

A final de año cuando se incrementan las precipitaciones, se incrementan los caudales de los ríos, especialmente el del rio Carinicuao, se produce un efecto notable, sobre los valores y concentraciones de los diferentes parámetros evaluados, lo cual se vio reflejado en la salinidad y densidad, especialmente en el sector más oriental del golfo. Igualmente se observó un mayor agotamiento del oxígeno disuelto tanto para el período de surgencia como para el de relajación, debido a la degradación de la materia orgánica, lo cual contribuyó a incrementar el amonio y bajar los valores del pH. También se incrementaron los valores de fosfato.

Durante el estudio se observó que los procesos de denitrificación fueron importantes en la reducción de las concentraciones de las especies oxidadas del nitrógeno e incremento de las reducidas, situación que se vio magnificada durante el período de relajación de la surgencia, especialmente en el sector más oriental del golfo. 
Tabla 4. Componentes principales de las variables hidroquímica de las aguas del sector oriental del golfo de Cariaco.

\begin{tabular}{|c|c|c|c|}
\hline \multicolumn{4}{|c|}{ Componertes } \\
\hline & 1 & 2 & 3 \\
\hline UAO & 0,11 & 0,48 & 0,04 \\
\hline $\mathrm{Chl}-a$ & $-0,18$ & 0,44 & $-0,05$ \\
\hline $\mathrm{NH}_{4}{ }^{\circ}$ & 0,37 & $-0,00$ & 0,02 \\
\hline $\mathrm{HO}_{2}^{-}$ & 0,12 & $-0,31$ & 0,41 \\
\hline $\mathrm{HO}_{3}^{-}$ & $-0,09$ & $-0,24$ & 0,47 \\
\hline Wstar & 0,16 & $-0,32$ & $-0,41$ \\
\hline $\mathrm{O}_{2}$ & $-0,03$ & $-0,49$ & $-0,04$ \\
\hline $\mathrm{pH}$ & $-0,45$ & 0,013 & $-0,10$ \\
\hline $\mathrm{PO}_{4}^{3-}$ & $-0,18$ & 0,022 & 0,54 \\
\hline S & $-0,44$ & $-0,08$ & $-0,03$ \\
\hline Sigmat & $-0,44$ & $-0,08$ & $-0,03$ \\
\hline $\mathrm{T}$ & 0,38 & $0, \infty 3$ & 0,14 \\
\hline$\% \mathrm{VE}$ & 39,59 & 25,04 & 17,28 \\
\hline$\% \mathrm{VA}$ & 39,59 & 64,63 & 81,91 \\
\hline $\begin{array}{l}\% \mathrm{VE}=\mathrm{Po} \\
\% \mathrm{VA}=\mathrm{Po}\end{array}$ & de var & $\begin{array}{l}\text { licativa } \\
\text { mulativ }\end{array}$ & \\
\hline
\end{tabular}

El estudio demostró que hay un desfase temporal entre el desarrollo del fitoplancton y las concentraciones de nutrientes, lo cual fue evidenciado con el comportamiento de la clorofila $a$.

Se observó una correlación negativa entre la clorofila $a$ y los nutrientes nitrogenados, lo cual sugiere que probablemente estos nutrientes jueguen un papel predominante en la nutrición del fitoplancton e incremento de los valores clorofila $a$, especialmente durante los eventos de surgencia costera. Sin embargo, se observaron evidencias de que el fósforo también fue importante en el desarrollo del fitoplancton, pudiendo limitar la producción, especialmente durante el período de relajación de la surgencia cuando la relación Redfiel se incrementó desde $\mathrm{N}: \mathrm{P}=16: 1$ hasta $\mathrm{N}: \mathrm{P}=24: 1$.

\section{REFERENCIAS}

Aminot, A. \& M. Chaussepied. 1983. Dosage del' Oxygénedissous. Aminot, A., Chaussepied, M. (Eds),Manuel des Analyses Chimiques en milieu MarinCentre National Pour L'..Explotation des Oceans, France. CNEXO. 125 pp.

Astor, F. Muller-Karger \& M. Scranton. 2003. Seasonal and interannual variation in the hydrographic of the Cariaco Basin: implications for basin ventilation. Cont. Shelf. Res. 125-144.
Bendschneider, K. \& R. Robinson. 1952. A new spectrophometric determination of nitrite in seawater. J. Mar. Res. 11:87-96.

BeníteZ, J. 1974. En revisión de los datos oceanográficos en el Mar Caribe Suroriental, especialmente margen continental de Venezuela. Cuadernos Azules 1(15). 110-124

Bonilla .J., G. Cedeño, B. Gamboa \& M. Cabrera. 1995. Aspectos geoquímicos de los sedimentos superficiales del ecosistema marino costero de Jose, Estado Anzoátegui. Venezuela. Bol. Inst. Oceanogr. de Venezuela 32 (1-2): 5-23.

, A. Márquez. \& B. Gamboa. 1985. Características geoquímicas en núcleos de sedimentos de la región nororiental y río Orinoco, Venezuela. Bol. Inst. Oceanogr. Venezuela. 24 (12): 43-61.

1982. Algunas características geoquímicas de los sedimentos superficiales del Golfo de Cariaco, Venezuela. Bol. Inst. Oceanogr. Venezuela 18(1\&2):133-155.

. 1993. Características hidroquímicas: Comportamiento y significados de modelos estadísticos multivariantes en el bi ecosistema marino costero de Jose, estado Anzoátegui. Trab. Asc. Universidad de Oriente. 231 pp.

., A. Quintero, J. Cordero, E. Basoa, B. Marín \& Y. Figueroa. 2003. Condiciones hidrográficas y químicas en la columna de agua de las adyacencias de la cuenca de Cariaco, estado Sucre, Venezuela. Saber (15):1 - 2: 106-112.

Bustos-Serrano, H \& R. Castro-Valdez. 2006. Flux of nutrients in the gulf of California: Geostrophic approach. Mar. Chem. 99. 210-219.

Caraballo, L. 1982b. El golfo de Cariaco. Parte II: Los sedimentos superficiales y su distribución por el fondo. Fuente de sedimentos. Análisis mineralógico. Bol. Inst. Oceanogr. Venezuela 21: 37 - 65.

Conejeros, R. 1986. Análisis de las condiciones hidrográficas y químicas en el área sur Oriental del 
Mar Caribe y las regiones adyacentes. Tesis de Postgrado. I.O.V, Universidad de Oriente, Venezuela.132 pp.

EsPinoza CarReón \& E. Valdez Holguin. 2007. Variabilidad interanual de la clorofila en el golfo de California. Ecol. Aplica. 6(1-2).83-92.

Febres-Ortega, G. 1974.Circulación de las aguas superiores de la fosa de Cariaco en Abril de 1974. Bol. Inst. Oceanogr. Venezuela 13 (1\&2)79-86.

Ferraz, E. 1989. Influencia de los factores físicos en la distribución vertical de la biomasa en el golfo de Cariaco, Venezuela. Bol. Inst. Oceanogr. Venezuela 28(1-2).47-56.

Fofonof, N. P \& R. Millard. C. 1983. Algorithms for computation of fundamental properties of sea water. UNESCO. Technical Papers in Marine Science. 44 : 15-19.

GRUBER, N \& J. SARMiENTO 1997. Global patterns of marine nitrogen fixation and denitrification. Global Biogeochem. Cycles 11(2), 235-266

Guzmán, R., G. Gómez \& M. Рenott. 1998. Aspectos biológicos y pesquería de la sardina (Sardinilla aurita) en el golfo de Cariaco, Venezuela. Zootec.Trop. 16(2): 149-162.

JoHnSON, R.A, D.W, WiCHERn. (1992). Applied multivariate statistical analysis. Prentice Hall International Editions. New York. Third Edition.156 pp.

KoROLEFF, F. 1969. Direct determination of ammonia innatural water as indophenols blue. Int. Count. Explor. Sea. C.M. 1969/C. 9: 19-22.

Libes, SM. 1992. An introduction to Marine Biogeochemistry. John Wiley \& Sons, New York, USA. 734 pp.

Margalef, R. 1965.Composición y distribución del fitoplancton. In: Estudios sobre el ecosistema pelágico del N.E. de Venezuela. Mem. Fund. Cienc. Nat. La Salle 25:141-208.

Márquez A., J. Bonilla G. Martínez, W. Senior, D.
Aguilera \& Á. González. 2005. Estudio geoquímico de los sedimentos superficiales del litoral nororiental del golfo de Cariaco, estado Sucre, Venezuela. Bol. Inst. Oceanogr. Venezuela 44 (2): 89-103

Martín, A., L. Malavé, D. Sánchez, R. Aparicio, F. Arocha, D. Bone, J. A. Bolaños, J. Bolaños-JimÉnEZ, J. Castañeda, J. J. CÁrdenas, A. K. Carbonini, Y. J. Díaz, H. J. Guada, E. Klein, R. Lazo, A. Lemus, M. Lentino, C. Lira, C. Lodeiros, R. López, B. Marín, G. Martínez, B. Márquez, A. Márquez, R. Molinet, F. Morales, J. Posada, A. Prieto, A. Riera, C. T. Rodríguez, A. Ramírez, W. Senior, P. Solana, H. Severeyn, P. Spiniello, E. Valera, C. Yanes \& E. Zoppr. 2007. En: Martín A, Bone D (Eds.). Línea Base Ambiental Plataforma Deltana. Petróleos de Venezuela, S. A. Univ Simón Bolívar. Caracas, Venezuela, 176pp.

Müller-Karger, F. \& R. Aparicio. 1994. Mesoscale processes affecting phytoplankton abundance in the Southern Caribbean Sea. Cont. Shelf. Res. 14:(2/ 3): 199-221

MurPhy, J. \& J. RiLey. 1962. A modified single solution method for the determination of phosphate in natural waters. Anal. Chem. Acta. 12:162-170.

Okuda, T., A. García, J. Bonilla, \& G. Cedeño. 1978. Características hidrográficas del golfo de Cariaco, Venezuela. Bol. Inst. Oceanog. Venezuela 17: 69-88.

. 1981. Water exchange and the balance of phosphate in the gulf of Cariaco, Venezuela. Coast. Estuar. Sci.1:274-281.

1982. Rate of waters renewal and phosphate input in the gulf of Cariaco, Venezuela. Bol. Inst. Oceanogr. Venezuela 21 (1-2): 3-12.

Platt, T \& S. Sathyendranath. 1999. Spatial structure of pelagic ecosystem processes in the global ocean. Ecosystem 384-394

Pnuma, 2009. Golfo de Cariaco (Venezuela). En. Programa de monitoreo de la calidad de ecosistemas marinos en zonas de alto riesgo en la región del gran Caribe. Informe Técnico PAC No. XX. PNUMA, Programa Ambiental del Caribe, Kingston. 65 pp. 
Quintero A., G. Terejova, G. Vicent, A. Padrón \& J. Bonilla. 2002. Los pescadores del golfo de Cariaco. Interciencia 27 (6) 286-292.

., L. Caraballo, J. Bonilla, G. Terejova \& R. Rivadula. 2003. Sedimentos marino costeros del golfo de Cariaco, Venezuela. Bol. Inst. Oceanogr. Venezuela. 45 (2): 127-139

Richard, F. 1963. Some chemical and hydrography observations along the north coast South America. Cabo Tres Puntas to Curacao, including the Cariaco trench and gulfo Cariaco. Deep. Sea.Res. 7 (3). 163-182.

Rowe, G., C. Clifford \& K. Smithz. 1977. Nutrient regeneration in sediments of Cap. Blanca Spanish Sahara. Deep. Sea. Res. 24:47-63.

SimPSON, J. \& R. GRIFFITH. 1967. La distribución de densidad pesquera en el Golfo de Cariaco, Venezuela. Serie: Recursos y explotación pesqueros. 1(8): 305-320.

Soto, G. 2011. Dinámica temporal en los nutrientes, relación con la hidrografía y el fitoplancton, en la ensenada de Turpialito, Edo. Sucre, Venezuela. Trab. Grad. Universidad de Oriente, Venezuela 123 pp.
STRICKLAND, J. \& T. PARSONS. 1972. A practical hand book of sea water analysis. Bull. Fish. Res. Bd. Canada, : $1-310$.

Treguer, P. \& P. Le Corre. 1975. Manual d'analyses dessels nutritifs dans l'eau de mer. Utilisation de 1' Auto-Analyzer II. Techicon. LOC-UBO. 2 da Eds. France. 110 pp.

UNESCO. 1986. Progress on oceanographic tables and standards 1983-1986. Work and recommendations of the UNESCO/SCOR/ICES/IAPSO Joint Panel. UNESCO Tech. Pap. Mar. Sci. 50: 59 pp.

VALDERRAMA, J. 1981. The simultaneous analysis of total nitrogen and total phosphorus in natural waters. Mar. Chem. 10: 109-122.

Valera, R. F. Carvajal \& F. Müller-Karger. 2003. El fitoplancton en la plataforma nororiental de Venezuela. IN: IRD Éditions. La sardina (Sardinella aurita), su medio ambiente y explotación en el Oriente de Venezuela. Paris, Francia. 551 pp.

Wood, E., F. Armstrong. \& L. Richards. 1967. Determination of nitrate in sea water by cadmium and copper reduction nitrite. J. Mar. Biol. Ass. U.K. 47: $23-31$

RECIBIDO: Julio 2011

AcEPTADO: Mayo 2012 